\title{
In-depth profiling and analysis of host and viral microRNAs in Japanese flounder (Paralichthys olivaceus) infected with megalocytivirus reveal involvement of microRNAs in host-virus interaction in teleost fish
}

\author{
Bao-cun Zhang ${ }^{1,2}$, Jian Zhang ${ }^{1,2}$ and Li Sun ${ }^{1,3^{*}}$
}

\begin{abstract}
Background: MicroRNAs (miRNAs) regulate gene expression by binding to mRNA transcripts in various biological processes. In mammals and birds, miRNAs are known to play vital parts in both host immune defense and viral infection. However, in lower vertebrates such as teleost, systematic investigations on host and viral miRNAs are lacking.

Results: In this study, we applied high-throughput sequencing technology to identify and analyze both host and viral miRNAs in Japanese flounder (Paralichthys olivaceus), an economically important teleost fish farmed widely in the world, infected with megalocytivirus at a timescale of 14 days divided into five different time points. The results showed that a total of 381 host miRNAs and 9 viral miRNAs were identified, the latter being all novel miRNAs that have no homologues in the currently available databases. Of the host miRNAs, 251 have been reported previously in flounder and other species, and 130 were discovered for the first time. The expression levels of 121 host miRNAs were significantly altered at $2 \mathrm{~d}$ to $14 \mathrm{~d}$ post-viral infection (pi), and these miRNAs were therefore classified as differentially expressed host miRNAs. The expression levels of all 9 viral miRNAs increased from $0 \mathrm{~d}$ pi to $10 \mathrm{~d}$ pi and then dropped from $10 \mathrm{~d}$ pi to $14 \mathrm{~d}$ pi. For the 121 differentially expressed host miRNAs and the 9 viral miRNAs, 243 and 48 putative target genes, respectively, were predicted in flounder. GO and KEGG enrichment analysis revealed that the putative target genes of both host and viral miRNAs were grouped mainly into the categories of immune response, signal transduction, and apoptotic process.

Conclusions: The results of our study provide the first evidences that indicate existence in teleost fish (i) infectionresponsive host and viral miRNAs that exhibit dynamic changes in expression profiles during the course of viral infection, and (ii) potential involvement of miRNAs in host-viral interaction.
\end{abstract}

Keywords: Iridovirus, microRNA, Paralichthys olivaceus, Teleost, Virus-host interaction

\section{Background}

MicroRNAs (miRNAs) are small non-coding RNAs with $\sim 22$ nucleotides (nt) in length. They have been recognized as crucial regulators of gene expression in plants and animals through interaction with specific mRNA targets and thereby affecting translation [1].

\footnotetext{
* Correspondence: Isun@qdio.ac.cn

'Key Laboratory of Experimental Marine Biology, Institute of Oceanology,

Chinese Academy of Sciences, Qingdao 266071, China

${ }^{3}$ Collaborative Innovation Center of Deep Sea Biology, College of Life

Sciences, Zhejiang University, Hangzhou 310058, China

Full list of author information is available at the end of the article
}

Functionally, miRNAs targeting on gene expression are involved in a range of biological processes, such as development, immunity, and apoptosis [2]. Dysregulation of miRNA production is often associated with diseased conditions, e.g. aberrant miRNA expression is a characteristic of all types of cancer. Consequently, miRNAs have been used as diagnostic and prognostic markers for cancer and other diseases [1,3-7].

MicroRNAs are key players in the regulation of various host-pathogen interactions. Accumulating reports have indicated that virus can produce miRNAs to manipulate 
host gene expression and facilitate viral replication [8]. On the other hand, the host limits viral infection through differentially expressing the miRNAs that target essential viral genes [9-12]. Compared to viral proteins, viral miRNAs are non-immunogenic, require less coding capacity, and can evolve rapidly to target new transcripts. Since the discovery of the first viral miRNAs in human B cells infected with Epstein-Barr virus (EBV) [13], more than 200 viral miRNAs have been identified in herpes virus, polyomavirus, ascovirus, and adenovirus [14]. Viral miRNAs contribute to infection through various mechanisms, notably immune evasion [15,16], induction of anti-apoptosis [17], reducing the antigenicity of viral proteins $[16,18]$, and promoting cell survival, proliferation, and differentiation [14].

With the development of high-throughput sequencing technology, more and more miRNAs associated with host-virus interactions have been discovered. These interactions include those between cytomegalovirus and humans [19], H1N1 influenza virus and mouse [20], avian influenza virus and chicken [21], and, for aquaculture virus, white spot syndrome virus (WSSV) and shrimp [22]. In lower vertebrates, a few studies on miRNAs associated with bacterial infection have been reported [23-25], however, systematic investigations on the role of miRNAs in interactions between lower vertebrate hosts (such as teleost) and viruses have not yet been documented.

Iridoviridae is a family of large viruses with linear, double-stranded DNA. The family is subdivided into five genera, of which, three genera, i.e., Lymphocystivirus, Ranavirus, and Megalocytivirus, are serious pathogens to a wide range of freshwater and marine fish including rock bream, turbot, Japanese flounder, orange-spotted grouper, catfish, sturgeon, largemouth bass, rainbow trout, and red sea bream [26-30]. However, the infection mechanism of iridovirus is largely unknown.

In this study, using Japanese flounder, an important economic teleost species, as a host model, we examined viral and host miRNAs associated with megalocytivirus infection by the approach of high-throughput sequencing. In addition, to facilitate understanding of the functional attributes of the miRNAs, the target genes of viral miRNAs and differentially expressed host miRNAs were predicted by in silico analysis and the gene ontology categories of the putative targets are described. Our results indicate for the first time that in teleost fish, the expression profiles of both host and viral miRNAs changed dynamically during the course of viral infection, and that miRNAs are most likely involved in the process of host-viral interaction.

\section{Methods}

\section{Animal ethics}

Experiments involving live animals were conducted in accordance with the "Regulations for the Administration of Affairs Concerning Experimental Animals" promulgated by the State Science and Technology Commission of Shandong Province. The study was approved by the Ethics Committee of Institute of Oceanology, Chinese Academy of Sciences.

\section{Fish}

Clinically healthy juvenile Japanese flounder (average size $11.3 \mathrm{~cm}$; average weight $12.4 \mathrm{~g}$ ) were purchased from a commercial fish farm in Shandong Province, China and maintained at $\sim 22^{\circ} \mathrm{C}$ in aerated seawater. Fish were acclimatized in the laboratory for two weeks before experimental manipulation. Before experiment, fish were randomly sampled for the examination of bacteria and megalocytivirus in blood, liver, kidney, and spleen as reported previously $[31,32]$. No bacteria or virus were detected from the examined fish. Before tissue collection, fish were euthanized with an overdose of tricaine methanesulfonate (Sigma, St. Louis, MO, USA) as reported previously [33].

\section{Experimental infection}

The fish viral pathogen megalocytivirus RBIV-C1 [32] was suspended in PBS to $1 \times 10^{6}$ copies $/ \mathrm{ml}$. Japanese flounder $(\sim 12.4 \mathrm{~g})$ were divided randomly into two groups and injected intraperitoneally with $100 \mu \mathrm{l}$ viral suspension. At 0 day (d), $2 \mathrm{~d}, 6 \mathrm{~d}, 10 \mathrm{~d}$, and $14 \mathrm{~d}$ post-infection (pi), fish (three at each time point) were euthanized, and spleen was collected under aseptic conditions and immediately stored in liquid nitrogen for later use. At each time point the spleen tissues of three fish were pooled together and used for subsequent small RNA sequencing.

\section{Sequencing of small RNAs}

Small RNA isolation, library construction, and highthroughput sequencing were all carried out by LC Science, Houston, USA. Briefly, total RNA was isolated from spleen tissues using mirVana ${ }^{\mathrm{Tm}}$ miRNA Isolation Kit (Life Technologies, USA) according to the manufacturer's instructions. The quantity and purity of the RNA were monitored using a NanoDrop ${ }^{\text {тм }} 1000$ spectrophotometer (Thermo Fisher Scientific, WI, USA) at $A_{260} / A_{280}>2.0$. The integrity of the RNA was analyzed using the Agilent 2100 Bioanalyzer system and RNA 6000 Nano LabChip Kit (Agilent, CA, USA) with RNA integrity number $(\mathrm{RIN})>$ 8.0. Approximately $1 \mu \mathrm{g}$ of total RNA was used to prepare small RNA library (16-30 nt) with TruSeq Small RNA Sample Prep Kits (Illumina, San Diego, USA), and single-end sequencing (36 bp) was performed on an Illumina Hiseq 2000 by LC Science (Houston, USA). 


\section{Analysis of sequencing reads}

A proprietary pipeline script, ACGT101-miR v4.2 (LC Sciences), was used for following sequencing data analysis: (i) generating unique families of sequenced sequences (SequSeqs) by sorting raw sequencing reads; (ii) filtering SequSeqs, in which the impurity sequences due to sample preparation, sequencing chemistry and processes, and the optical digital resolution of the sequencer detector were removed; (iii) discarding SequSeqs mapped to RFam database (http://rfam.janelia. org) and RepBase (http://www.girinst.org/repbase); (iv) mapping miRNA Unique Seqs to pre-miRNA (mir) and expressed sequence tag (EST), during which various mappings were performed on unique sequences against mir and mature miRNA (miR) sequences listed in miRBase 20.0 (http://www.mirbase.org/search.shtml) with an E value similarity cutoff of 1e-10. Meanwhile, Bowtie-1.0.0 (http://bowtie-bio.sourceforge.net) was also applied to find the reads mapped to the miRbase with the following criteria: (i) the length of seed sequence is $16 \mathrm{nt}$, and (ii) the error allowable in seed region is $1 \mathrm{nt}$. To identify novel miRNA, the remaining high-quality sequences that have no homologues in miRBase 20.0 but can map to the hairpin structures of flounder ESTs or RBIV-C1 genome were further analyzed and considered candidates of novel miRNA if they possess the following characteristics: (i) number of nucleotide in one bulge in stem $<=12$, (ii) number of base pair in the stem region of the predicted hairpin $>=16$, (iii) cutoff of free energy $(\mathrm{kCal} / \mathrm{mol})<=-15$, (iv) length of hairpin (up and down stems + terminal loop) $>=50$, (v) length of hairpin loop $<=20$, (vi) number of nucleotide in one bulge in mature region $<=4$, (vii) number of biased error in one bulge in mature region $<=2$, (viii) number of biased bulge in mature region $<=2$, (ix) number of error in mature region $<=4$, ( $\mathrm{x}$ ) number of base pair in the mature region of the predicted hairpin $>=12$, (xi) percent of mature region in stem $>=80$ [34]. For cross-comparisons of miRNAs at different time points of infection, the number of miRNA reads was normalized with Bonferroni correction, and significant expression differences were assessed with Chi-square test and Fisher exact test.

Real-time quantification of miRNAs by stem-loop RT-PCR Total RNAs from the spleens of Japanese flounder at different infection times were isolated using RNAiso plus kit (TaKaRa, Dalian, China) and then treated with DNase I (TaKaRa, Dalian, China) to remove remaining DNA. One microgram of total RNA was reverse transcribed to cDNA using RevertAid First Strand cDNA Synthesis Kit (Thermo Scientific Fermentas, Beijing, China) and stem-loop reverse transcription (RT) primers (Additional file 1). The mix was incubated at $42^{\circ} \mathrm{C}$ for $60 \mathrm{~min}$ and then at $70^{\circ} \mathrm{C}$ for $5 \mathrm{~min}$. Quantitative real-time
PCR was carried out in an Eppendorf Mastercycler (Eppendorf, Hamburg, Germany) in a $20 \mu \mathrm{l}$ reaction volume containing $1 \mu \mathrm{l}$ cDNA, $10 \mu \mathrm{l}$ SYBR Premix Ex Taq ${ }^{\mathrm{Tm}} \mathrm{II}$ (TaKaRa, Dalian, China), $0.2 \mu \mathrm{l}$ specific forward primer $(20 \mu \mathrm{M}), 0.2 \mu \mathrm{l}$ reverse primer $(20 \mu \mathrm{M})$, and $8.6 \mu \mathrm{l}$ water. The reaction was performed at $95^{\circ} \mathrm{C}$ for $5 \mathrm{~min}$, followed by 45 cycles of $94^{\circ} \mathrm{C}$ for $15 \mathrm{~s}, 60^{\circ} \mathrm{C}$ for $15 \mathrm{~s}$, and $72^{\circ} \mathrm{C}$ for $15 \mathrm{~s}$. The abundance of miRNAs was normalized relative to that of $5 \mathrm{~S}$ rRNA as reported previously [35]. All reactions were performed in triplicate. The threshold cycle (Ct) was determined using the default threshold settings, and the data were analyzed using $2^{-\Delta \Delta C t}$ program. The experiment was performed independently three times.

\section{Prediction and analysis of the target genes of miRNAs}

The putative 3'- untranslated regions (UTRs) of flounder mRNAs were used for the prediction of miRNA target genes with TargetScan 6.2 (http://www.targetscan.org/) and miRanda (http://www.microrna.org/). TargetScan was used to search for miRNA seed matches (nucleotides 2-8 from the 5 ' end of miRNA) in 3'-UTR sequences. miRanda was used to match the entire miRNA sequences. The parameters of TargetScan and miRanda were set as score $>50$ and free energy $<-20 \mathrm{kcal} / \mathrm{mol}$ respectively. The results predicted by the two algorithms were combined, and the overlaps were calculated. Enrichment analysis of the predicted target genes was conducted with Gene Ontology (GO) (http://www.geneontology.org/) and KEGG pathway (http://www.genome.jp/kegg/). A heatmap chart was drawn by transforming the normalized data to a $\log 2$ scale for visualization purpose. Hierarchical clustering was performed using the gplots heatmap. 2 of $R$ program.

\section{Results}

Identification of host (Japanese flounder) miRNAs

In order to identify the miRNAs involved in viral infection and host immune response, Japanese flounder were infected with megalocytivirus for $0 \mathrm{~d}, 2 \mathrm{~d}, 6 \mathrm{~d}, 10 \mathrm{~d}$, and $14 \mathrm{~d}$. Small-fragment RNA libraries representing the five time points were constructed and subjected to sequence analysis. A total of $61,863,062$ raw sequences were obtained. After removing reads without 3 ' adaptor, $<16$-base reads, $>29$-base reads, and junk reads, 50,746,504 reads were mappable to RFam database, RepBase, miRBase 20.0, the hairpin regions of flounder EST database, and the hairpin regions of the genome sequence of megalocytivirus RBIV-C1 (GenBank accession no. KC244182) (Figure 1A). For the sequences mapped to miRBase 20.0 and the hairpin regions, length distribution analysis indicated that the majority of sequences were distributed in the 20-23 nucleotides (nt) range, and that 22-nt sequences were the most abundant, with the exception for the $10 \mathrm{~d}$ post-infection (pi) group, which contains predominantly 


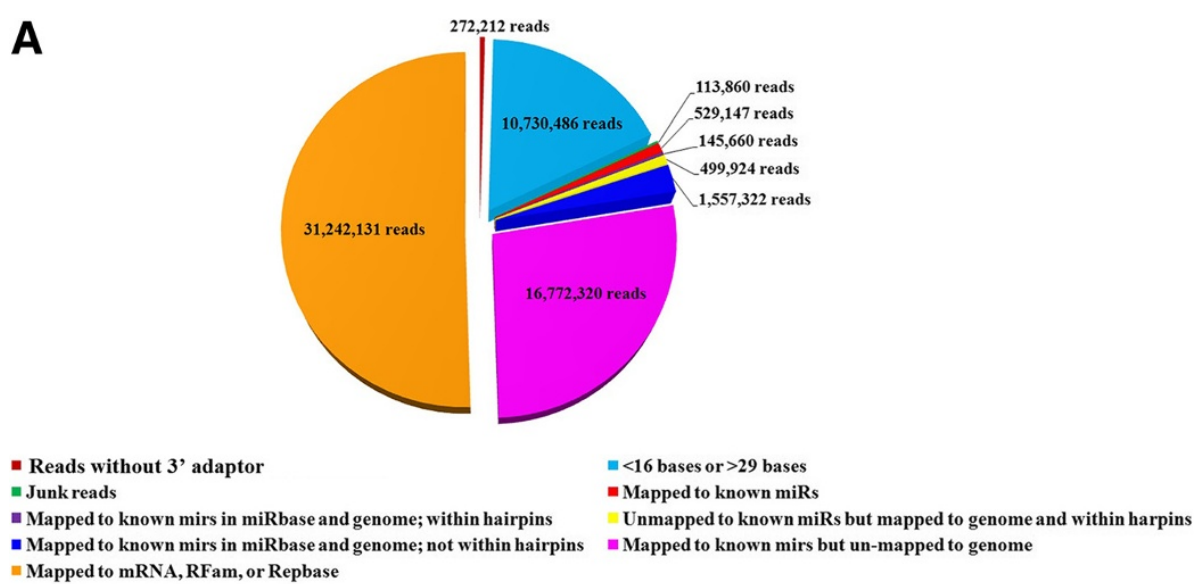

B

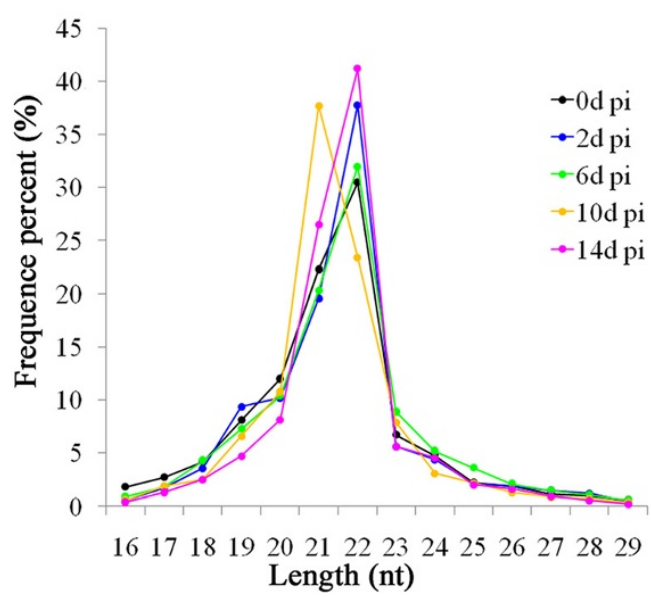

Figure 1 Analysis of the sequencing reads of flounder small RNAs at different times of megalocytivirus infection. (A) Summary of the sequencing reads. (B) Length distributions of the sequencing reads after removing 3 ' adaptor-missing reads, $<16$ bases reads, $>29$ bases reads, junk reads, and reads mapped to RFam database and RepBase. nt, nucleotide.

21-nt sequences (Figure 1B). BLAST against miRBase 20.0 showed that, with an E-value similarity cutoff of $1 \mathrm{e}-10$ and allowing for one or two mismatches, 26 reads were mapped to the known miRNAs of flounder, and 225 reads show sequence similarities with the miRNAs of other bony fishes as well as reptiles, birds, and mammals (Additional file 2). Hence, 251 miRNAs with known homologues were found. For the remaining reads, 2,588 were mapped to the hairpin structures of flounder ESTs. Further analysis (based on the principles described in Methods, section "Analysis of sequencing reads") revealed that 130 of the 2,588 reads are novel flounder miRNAs which have no known homologues (Additional file 2, pol-miR-3p-1043040_2 to pol-miR5p-96_67419). Taken together, a total of 381 flounder miRNAs were identified.

Of the 251 flounder miRNAs that have known homologues in different animal species, pol-miR-133a-3p_L-1R + 1 is most widely distributed, with counterparts existing in zebrafish, Japanese killifish, mouse, humans, common chimpanzee, pig, platypus, Carolina anole, pipid frog, chicken, and zebra finch (Additional file 2). Other flounder miRNAs with relatively abundant distributions in vertebrates and invertebrates are pol-miR-101a, pol-miR124-3p_R-2, pol-miR-140-3p_R + 1, pol-miR-140-5p, pol-miR-153-5p, pol-miR-153a, pol-miR-19a-5p_L-1R + 1, pol-miR-190a, pol-miR-199a-5p_R +1, and pol-miR455a_R-1. For example, pol-miR-19a-5p_L-1R + 1 exhibits homology with the miRNAs of age-mir-19a (spider monkey), tgu-mir-19a (zebra finch), hsa-miR-19a-5p (human), gga-miR-19a-5p (chicken), mml-miR-19a-5p (rhesus monkey), and mdo-miR-19a-5p (gray short-tailed opossum) (Additional file 2). In general, most of the homologues of flounder miRNAs were found in zebrafish.

\section{Identification of viral miRNAs}

Of the 50,746,504 mappable RNAs obtained above, 292 reads perfectly match the RBIV-C1 genome sequence. When these reads were aligned to known viral miRNAs deposited at miRBase 20.0, no homologues were found. 
The reads plus the extended sequences in RBIV-C1 genome were scanned to identify regions with hairpin-forming potential. Based on this potential and other characteristics defined in the principles described in Methods (section "Analysis of sequencing reads"), nine reads were identified as candidates of novel viral miRNAs (Additional file 1). These miRNAs distribute throughout the RBIV-C1 genome and are derived from eight imperfect fold-back structure precursors (Figure 2). Seven of these miRNAs are located at the 5'-arm (5p) or the 3'-arm (3p) of pre-miRNAs, and two, i.e., M-miR-4-5p and M-miR-4-3p, are derived from the same pre-miRNA (Figure 2A). Six miRNAs are located in coding regions, one (M-miR-6-5p) is between two adjacent coding regions, and two (M-miR4-5p and M-miR-4-3p) overlap the terminus of the same coding region. Furthermore, of the six miRNAs located in coding regions, three are in the same transcription orientations as the corresponding coding regions, while the other three are transcribed from the opposite directions to the coding regions (Figure 2B).

\section{Expression patterns of the novel viral miRNAs during the course of infection}

To examine the expression levels of the nine novel viral miRNAs at different infection time points, the amounts of the miRNAs were normalized with Bonferroni correction. The results showed that all nine miRNAs increased as infection progressed until $10 \mathrm{~d}$ pi and then dropped at $14 \mathrm{~d}$ pi (Figure 3A). Only one miRNA, M-miR-1-5P, was detected at both early and late infection stages. To validate the authenticity of these expression patterns, stem-loop RT-PCR was performed to determine the expression levels of the nine miRNAs at $0 \mathrm{~d}$ pi, $2 \mathrm{~d}$ pi, $6 \mathrm{~d}$ pi, $10 \mathrm{~d}$ pi, and 14 $\mathrm{d}$ pi. The results showed that the expression profiles of all nine miRNAs were largely similar to those determined by high-throughput sequencing (Figure 3B).

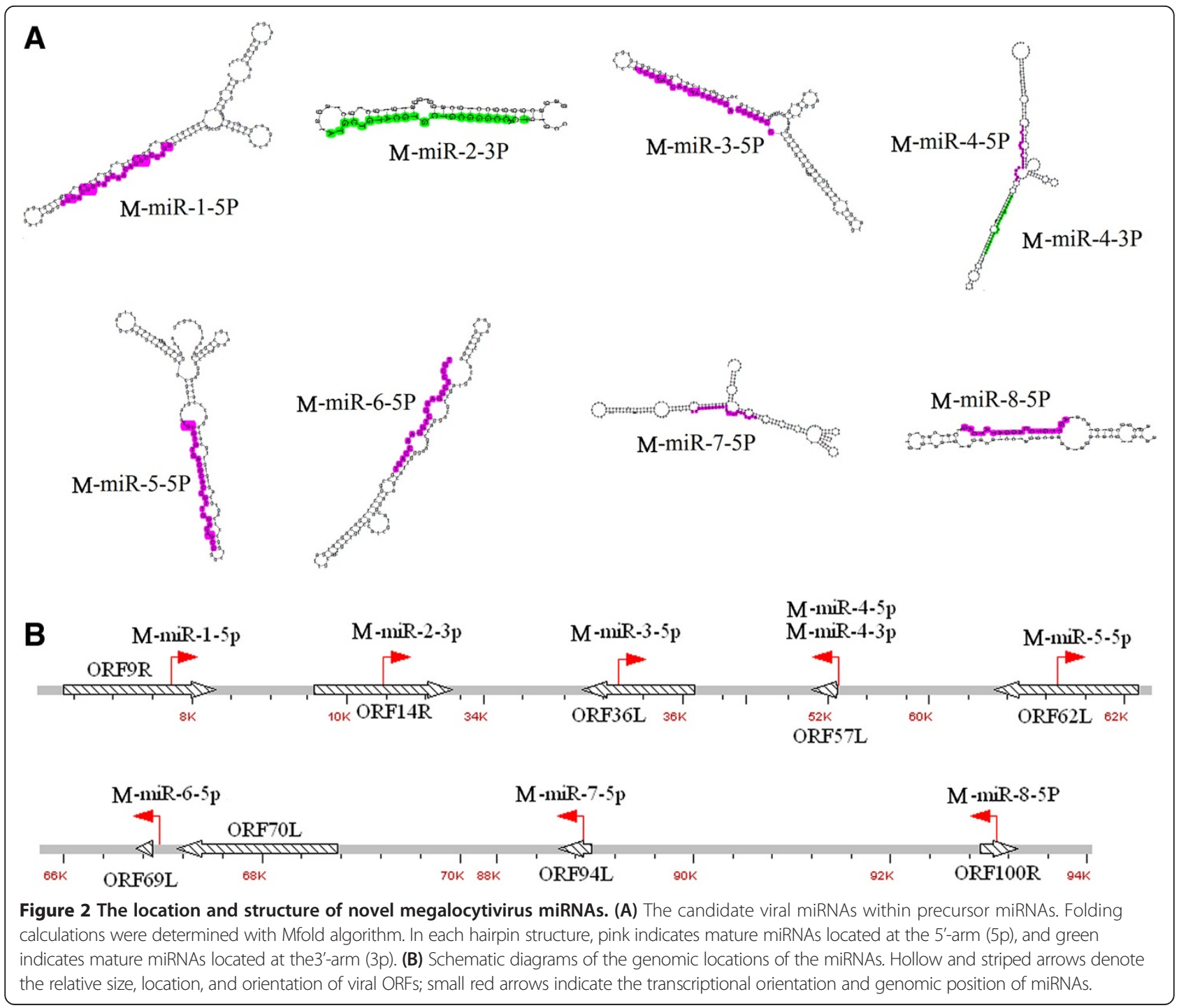




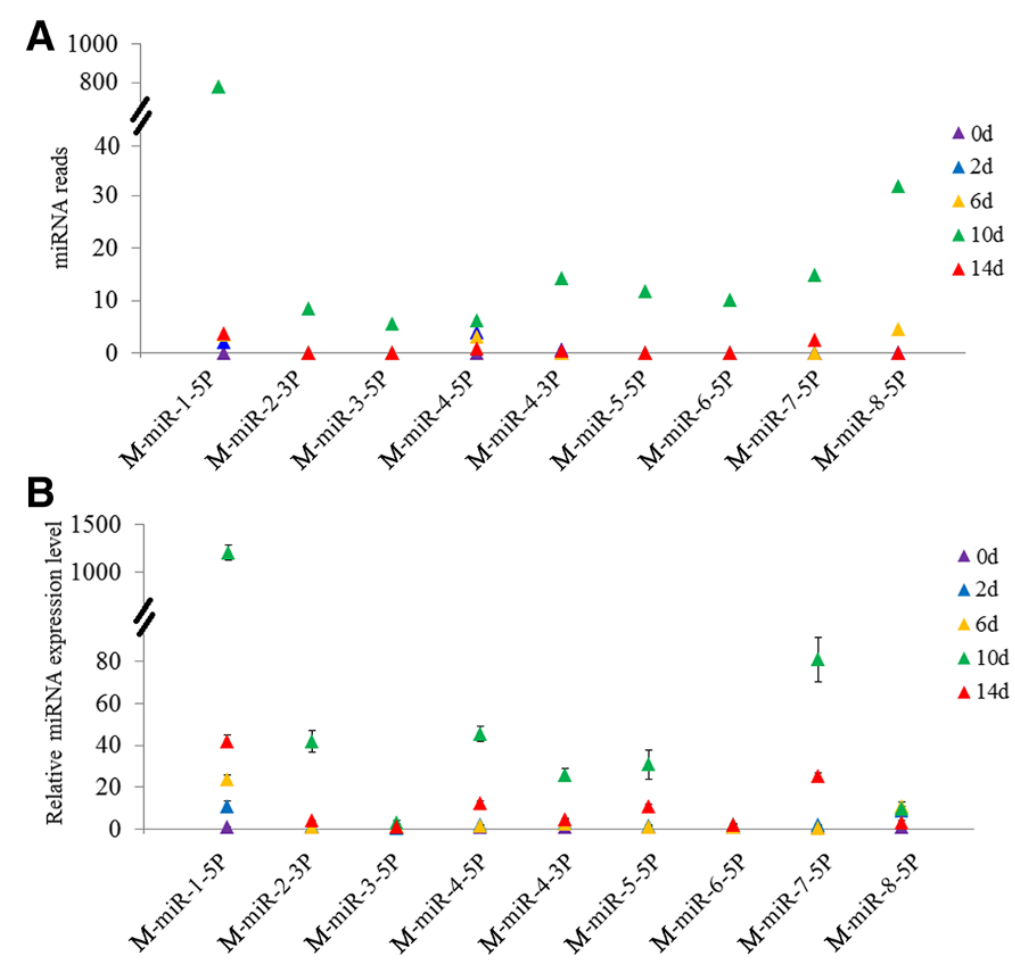

Figure 3 Expression of the nine novel megalocytivirus miRNAs during the course of infection. The expression levels of the viral miRNAs at different days (d) of infection were determined with high-throughput sequencing (A) and stem-loop relative quantitative RT-PCR (B). In panel B, values are shown as means \pm SEM $(N=3)$. $N$, the number of times the experiment was performed.

\section{Differentially expressed host miRNAs induced by viral infection}

To identify host miRNAs involved in viral infection, the expression profiles of the 381 flounder miRNAs were examined at $0 \mathrm{~d}$ pi, $2 \mathrm{~d}$ pi, $6 \mathrm{~d}$ pi, $10 \mathrm{~d}$ pi, and $14 \mathrm{~d}$ pi, and the amounts of miRNA were normalized with Bonferroni correction. The results showed that 345 miRNAs expressed at all examined time points, while three, six, five, seven, and two miRNAs expressed specifically at $0 \mathrm{~d}$ pi, $2 \mathrm{~d}$ pi, $6 \mathrm{~d}$ pi, $10 \mathrm{~d}$ pi, and $14 \mathrm{~d}$ pi respectively (Figure 4, Additional file 3). Compared to the expression levels at $0 \mathrm{~d}$ pi, the expression levels of 121 miRNAs at $2 \mathrm{~d}$ pi to $14 \mathrm{~d}$ pi were significantly $(P<0.01)$ changed. Specifically, 11 miRNAs (including pol-miR-430a-18-p5_1ss2GA, pol-miR-130a, and pol-miR-499_R-1) were significantly upregulated at $2 \mathrm{~d}$ pi, 30 miRNAs (including dre-miR-184_R-2, pol-miR-3p-214100_6, pol-miR-19b-5p_R + 1, pol-miR459-5p_R + 1, pol-miR-194a_R + 1, and pol-miR-203-3p) were significantly downregulated at $2 \mathrm{~d}$ pi, 15 miRNAs (including pol-miR-3p-258753_5, pol-miR-202-5p_R-1, pol-miR-5p-166774_9, and pol-miR-5p-106275_22) were significantly upregulated at $6 \mathrm{~d}$ pi, 14 miRNAs (including, pol-miR-459-5p_R + 1, pol-miR-735-p3_1ss13CG, pol-miR100-1-p3_1ss17TC, pol-miR-5p-450994_3, and pol-miR-5p652209_2) were significantly downregulated at $6 \mathrm{~d}$ pi,
41 miRNAs (including pol-miR-3p-676345_2, pol-miR-3p242304_6, pol-miR-5p-740108_2, and pol-miR-5p-285628_4) were significantly upregulated at $10 \mathrm{~d}$ pi, 19 miRNAs (including pol-miR-726_R + 1, pol-mir-734-p5_1ss2GT, pol-mir-100-1-p3_1ss17TC, and pol-mir-10b-2-p3) were

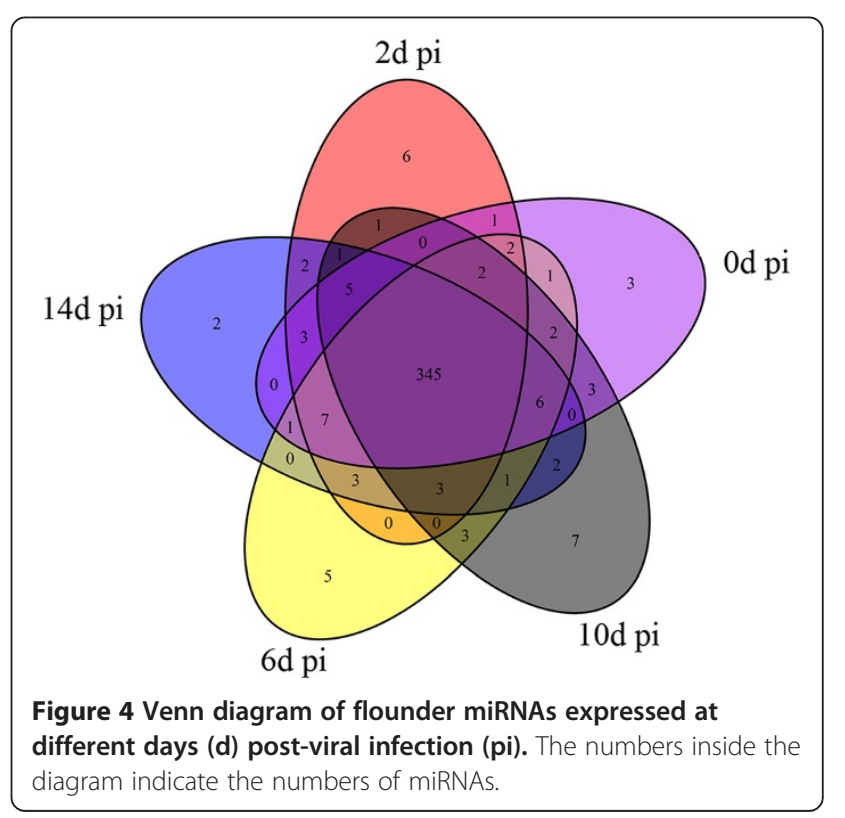


significantly downregulated at $10 \mathrm{~d}$ pi, 28 miRNAs (including pol-miR-202-5p_R-1, pol-miR-155_R + 1, polmiR-3p-496983_3, pol-miR-146b_R-6, and pol-miR375_R-1) were significantly upregulated at $14 \mathrm{~d}$ pi, and 29 miRNAs (including pol-mir-100-1-p3_1ss17TC, pol-miR-199a-5p_2ss10CT17CT, pol-miR-5p-467249_3, pol-miR-146, pol-miR-221-5p, pol-miR-221-3p, and pol-miR-3p-192896_7) were significantly downregulated at $14 \mathrm{~d}$ pi (Figure 5A). To validate the expression patterns of the miRNAs, stem-loop RT-PCR was conducted to examine the mRNA levels of ten randomly selected miRNAs. The results showed that the expression profiles of all ten miRNAs were essentially similar to those determined by high-throughput sequencing (Figure 6). For all differentially expressed miRNAs, in order to observe their expressions along with the infection process, a heat map was drawn, and clustering analysis was conducted based on similar expression patterns (Figure 7). The results showed that all differentially expressed miRNAs were grouped together by $k$-means clustering. As the infection progressed, the expressions of the miRNAs exhibited dynamic changes and formed various patterns, including sustained upregulation/downregulation during the entire infection period, upregulation/downregulation followed by downregulation/ upregulation, and diphasic expression patterns.

\section{Prediction of the target genes of host miRNAs}

Potential targets of the 121 differentially expressed host miRNAs were predicted using Targetscan 6.2 and miRanda algorithms. The results showed that for 107 miRNAs, 800 putative target sites in 243 flounder genes were predicted (Additional file 4), while for the remaining 14 differentially
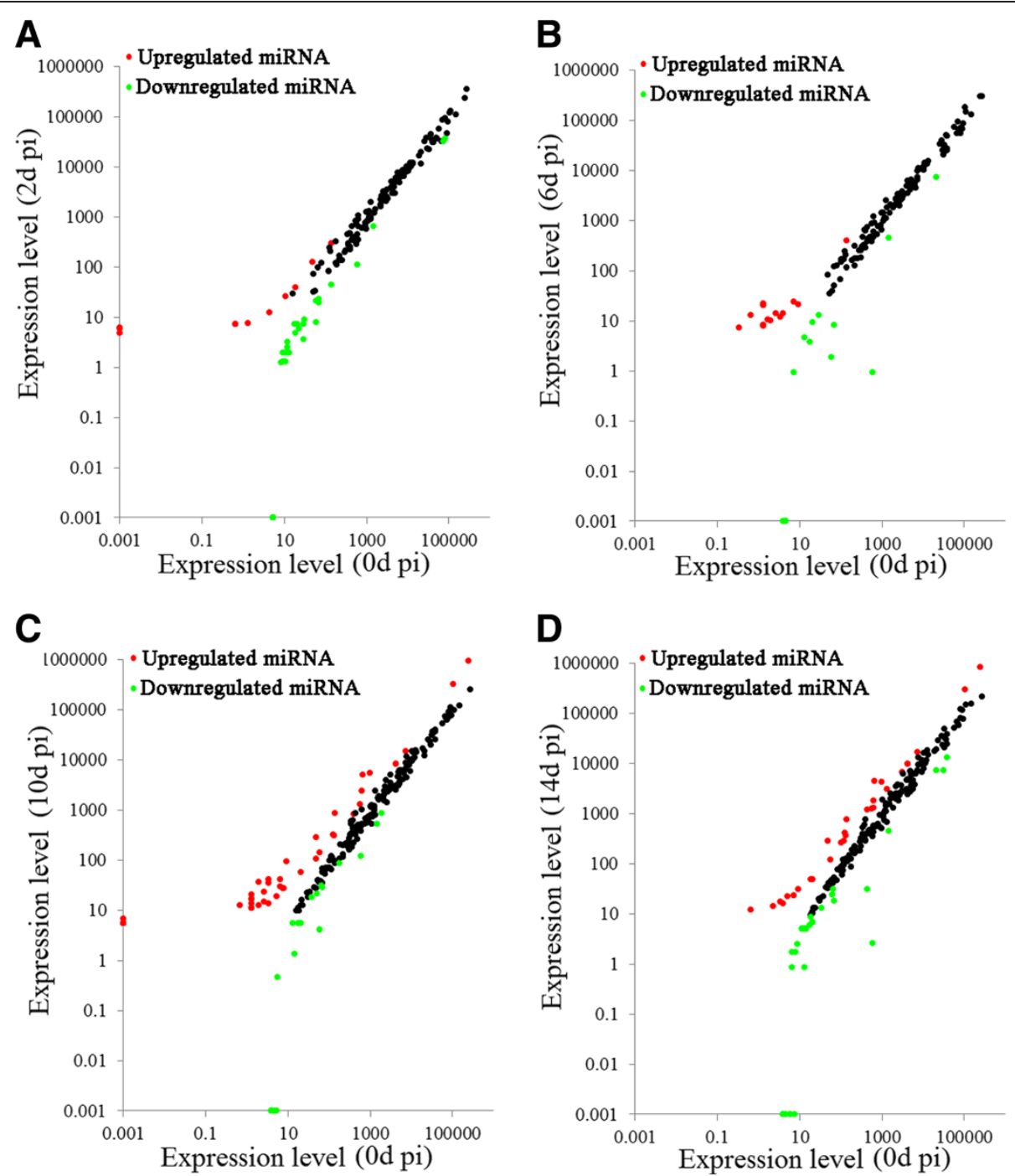

Figure 5 Effect of megalocytivirus infection on the expression of flounder miRNAs. Scatter plot of the expression levels of flounder miRNAs at $2 \mathrm{~d}(\mathbf{A}), 6 \mathrm{~d}(\mathbf{B}), 10 \mathrm{~d}(\mathbf{C})$, and $14 \mathrm{~d}$ (D) post-viral infection (pi) in comparison with that at $0 \mathrm{~d}$ pi. Red and green spots represent miRNAs that are significantly $(P<0.01)$ upregulated and downregulated respectively. 


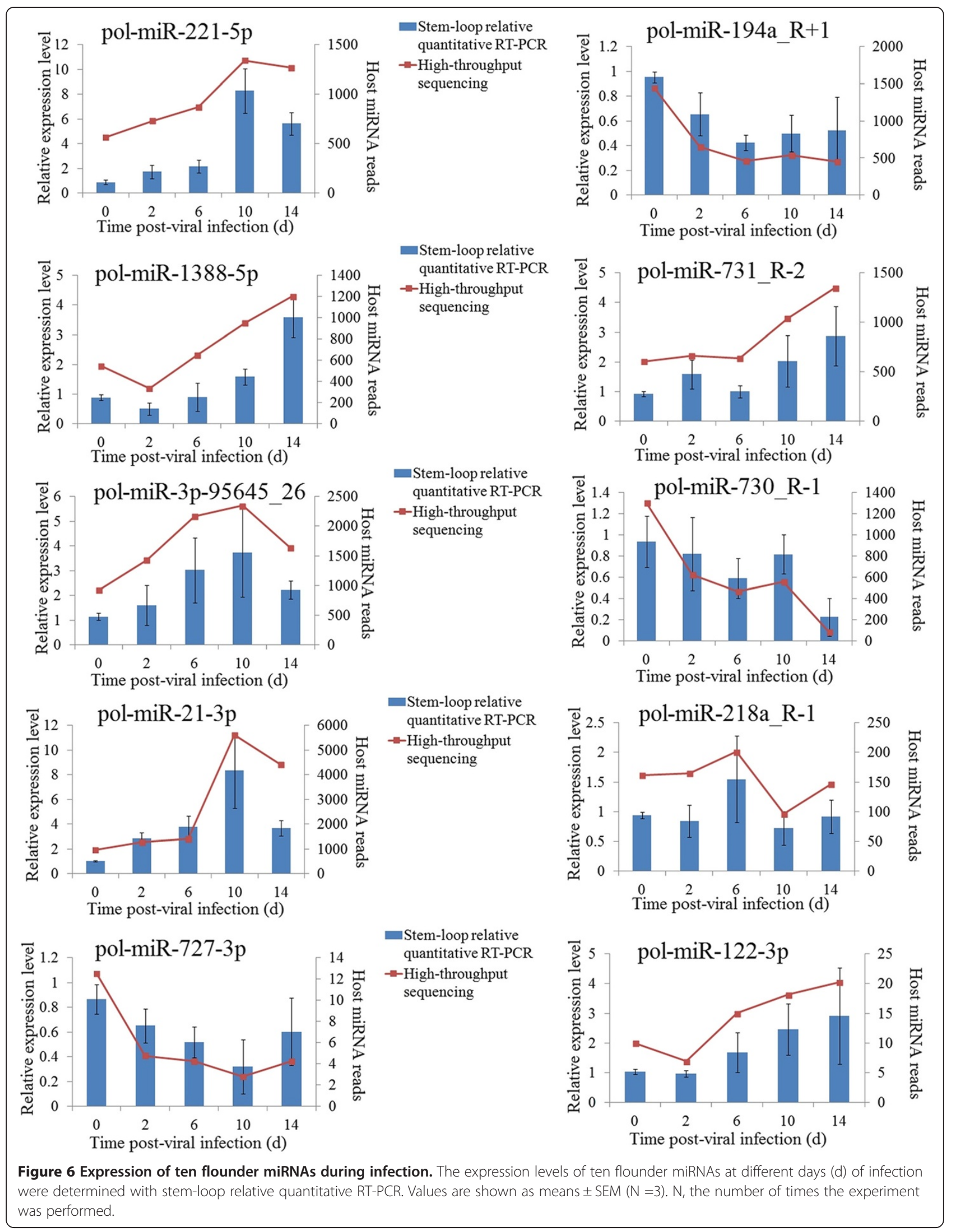


Figure 7 Clustering of the expression patterns of 121 host miRNAs expressed differentially during viral infection. The expression levels of the 121 miRNAs at $0 \mathrm{~d}$ to $14 \mathrm{~d}$ post-infection (dpi) are shown in different colors. Each horizontal color bar represents one miRNA, with the name of the miRNA indicated on the right of the bar.

expressed miRNAs, no target sites in flounder were found. The 243 putative target genes cover a wide range of functions, notably those related to immunity (Additional file 5: Table S1). Immune relevant genes include interleukin (IL)-8 targeted by pol-miR-3p$511642 \_4$, interferon-induced $\mathrm{Mx}$ protein $(\mathrm{Mx})$ targeted by pol-miR-199-3-p3 and pol-miR-459-5p_R + 1, T cell receptor (TCR) targeted by pol-miR-192-p3 and pol-miR3p-242304_6, interferon regulatory factor (IRF) 7 targeted by pol-miR-194a_R +1 and pol-miR-301c_R +1 , C-type lectin targeted by pol-miR-153-5p, pol-miR-200b-p5 and pol-miR-20b_R-1_1ss1CA, complement component 3 (C3) targeted by pol-miR-203-3p, p65 NF-kB targeted by polmiR-221-3p and pol-miR-222a_R-1, toll-like receptor (TLR) 3 targeted by pol-miR-129-3p, pol-miR-221-5p, pol-miR221-3p, and pol-miR-200b-p5, myeloid differentiation factor 88 (Myd88) targeted by pol-miR-146a, cathepsin B targeted by pol-miR-203-3p, type 1 insulin-like growth factor receptor fIGF-IR-2 targeted by pol-miR194a_R + 1 and pol-miR-459-5p_R + 1, and transcription factor PU.1 targeted by pol-miR-459-5p_R + 1 .

\section{Enrichment analysis of the putative target genes of host miRNAs}

To get an overview of the pathways in which host miRNAs were involved, the putative target genes of the differentially expressed host miRNAs were subjected to GO analysis and KEGG pathway analysis. GO enrichment analysis based on biological process showed that the 243 predicted target genes of flounder were clustered into 296 GO terms. The top ten enriched GO terms are associated with signal transduction, proteolysis, transcription regulation, immune response, stress and infection response, phosphorylation, oxidation-reduction process, lipid metabolic process, and protein folding (Figure 8A). To examine the effect of the miRNAs in more detail, another GO analysis was conducted, in which the 121 differentially expressed host miRNAs were grouped into upregulated and downregulated categories at each infection time point, and then GO analysis was performed on the target genes of the miRNAs in each category. The results revealed an interesting trend, i.e., the numbers of target genes in all pathways changed at different time points (Figure 8C). For example, at $2 \mathrm{~d}$ pi, the genes belonging to the $\mathrm{GO}$ terms of proteolysis, apoptotic process, innate immune response (in particular inflammatory response), antigen processing and presentation, and phosphorylation were preferably targeted by 


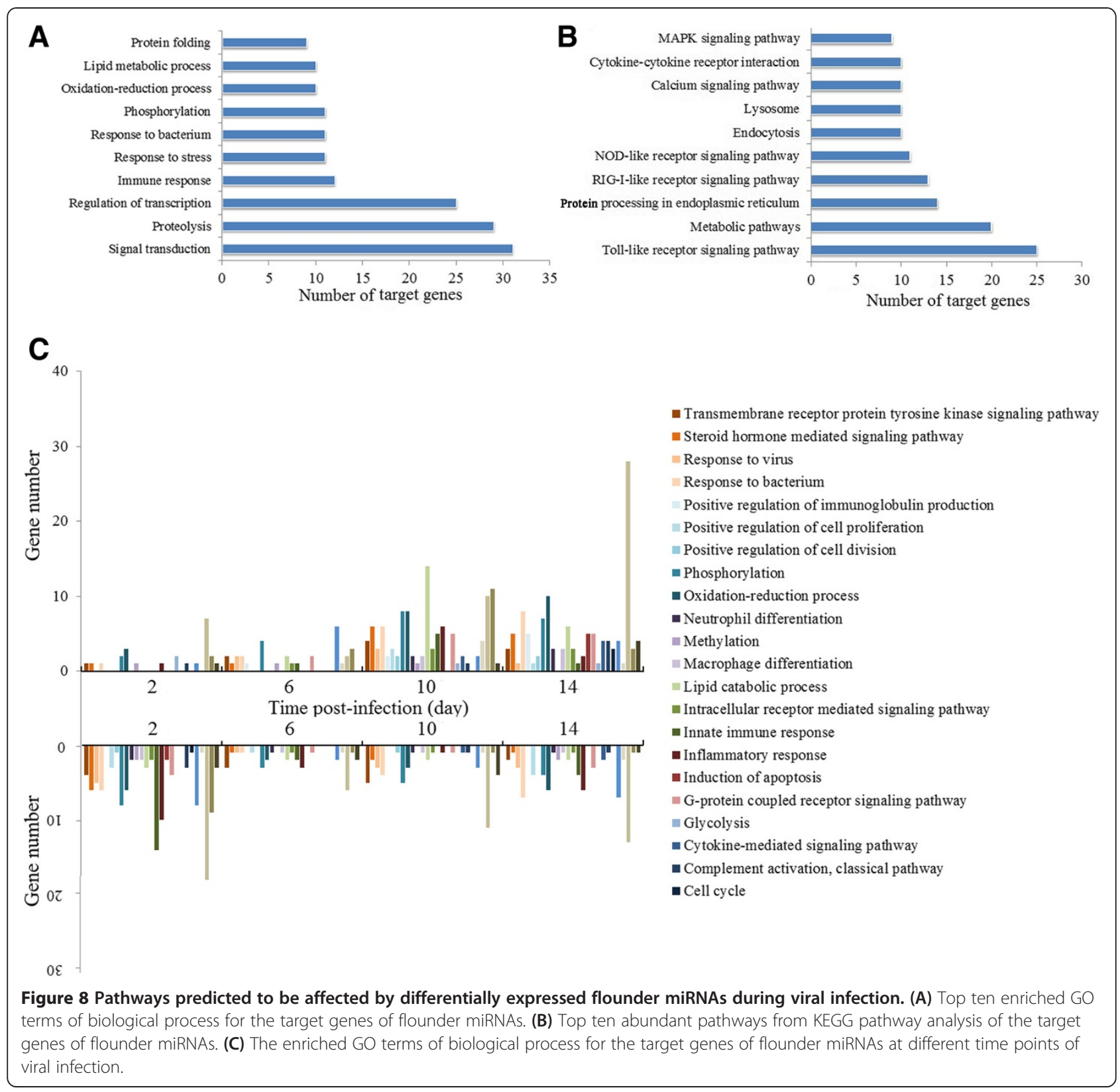

downregulated miRNAs; at $6 \mathrm{~d}$ pi, relatively few target genes were enriched into GO terms; at $10 \mathrm{~d}$ pi, fourteen, ten, and eleven genes targeted by downregulated miRNAs were enriched into the processes of lipid catabolism, apoptosis, and antigen processing/presentation respectively; at $14 \mathrm{~d} \mathrm{pi}$, genes involved in apoptotic process were the highest in number among the genes targeted by upregulated miRNAs.

Similar to GO analysis, KEGG pathway analysis showed that the putative target genes predicted in flounder were grouped into 64 pathways. The top ten enriched pathways were involved in TLR signaling, metabolism, protein processing in endoplasmic reticulum, RIG-I-like receptor signaling, NOD-like receptor (NOD-RC) signaling, endocytosis, lysosome, calcium signaling, cytokine-cytokine receptor interaction, and MAPK signaling (Figure 8B).

\section{Prediction and enrichment analysis of the putative target genes of viral miRNAs}

For the nine novel viral miRNAs, target prediction identified 56 putative target sites in flounder, which are distributed among 43 genes. GO analysis showed that most of the predicted target genes of viral miRNAs are related to signal transduction and immune response. The immune relevant genes include TLR14, IRF3, NOD-RC, tumor necrosis factor receptor-1 (TNFR-1), voltage-dependent anion channel (VDAC), and complement 
component 9 (C9), which are targeted by M-miR-5-5P, M-miR-2-5P, M-miR-2-5P, M-miR-4-5P, M-miR-7-5P, and M-miR-5-5P respectively (Figure 9). These putative target genes were all clustered into the innate immunity GO term. M-miR-4-5P was also predicted to target double-stranded (ds) RNA-dependent kinase (PKR), growth differentiation factor-15 (GDF-15), and tumor necrosis factor alpha (TNF- $\alpha$ ). TNF- $\alpha$ was grouped into the GO terms of apoptotic process and innate immunity. For the remaining miRNAs, M-miR-3-5P was predicted to target immunoglobulin $\beta$ (CD79B), which was assigned to adaptive immunity $\mathrm{GO}$ term; M-miR-2-3P and M-miR-5-5P target cathepsin B, F, and $\mathrm{Z}$, which were classified into lysosome GO term. In addition, of the 43 flounder genes targeted by viral miRNAs, 39 genes were also targeted by host miRNAs; however, no identical target sites in these genes were found for host and viral miRNAs.

\section{Discussion}

In this study, we identified and investigated the expression patterns of both viral and host miRNAs in a teleost fish, Japanese flounder, infected with megalocytivirus at different time points. We detected 381 host miRNAs, of which 130 were discovered for the first time. These novel miRNAs add to the known miRNAs pools of fish. Previous studies showed that viral infection can profoundly influence the expression of host miRNAs [36-41]. In humans, distinct miRNA expression profiles were observed after HIV infection $[42,43]$. Likewise, avian influenza virus infection changed the expression of a large amount of miRNAs in the lung and trachea of chicken [21]. Similar studies in lower vertebrates, including fish, have not been reported before this study. In this study, we found that 121 host miRNAs displayed significantly different expressions during viral infection, suggesting that megalocytivirus altered, on a large scale, the regulation of miRNA expression in flounder. These results indicate the possibility that, as observed in higher vertebrates, miRNAs likely participate in host-virus interaction in teleost.

Detailed analysis of the expression profiles of flounder miRNAs on a timescale of 14 days revealed that dynamic changes were associated with the course of megalocytivirus infection, and that the expression levels of individual miRNAs varied at different time points. These observations support the hypothesis that different miRNAs may have different roles, which are played out at different infection stages. It is possible that the differentially expressed host miRNAs may act on the host itself, such as regulating gene expression in flounder, or on virus, such as modifying the expression of the genes of megalocytivirus. For regulation of host genes, two possibilities exist, one is that the host miRNAs actively exert their functions in a natural manner that promotes viral clearance, and the other is that the host

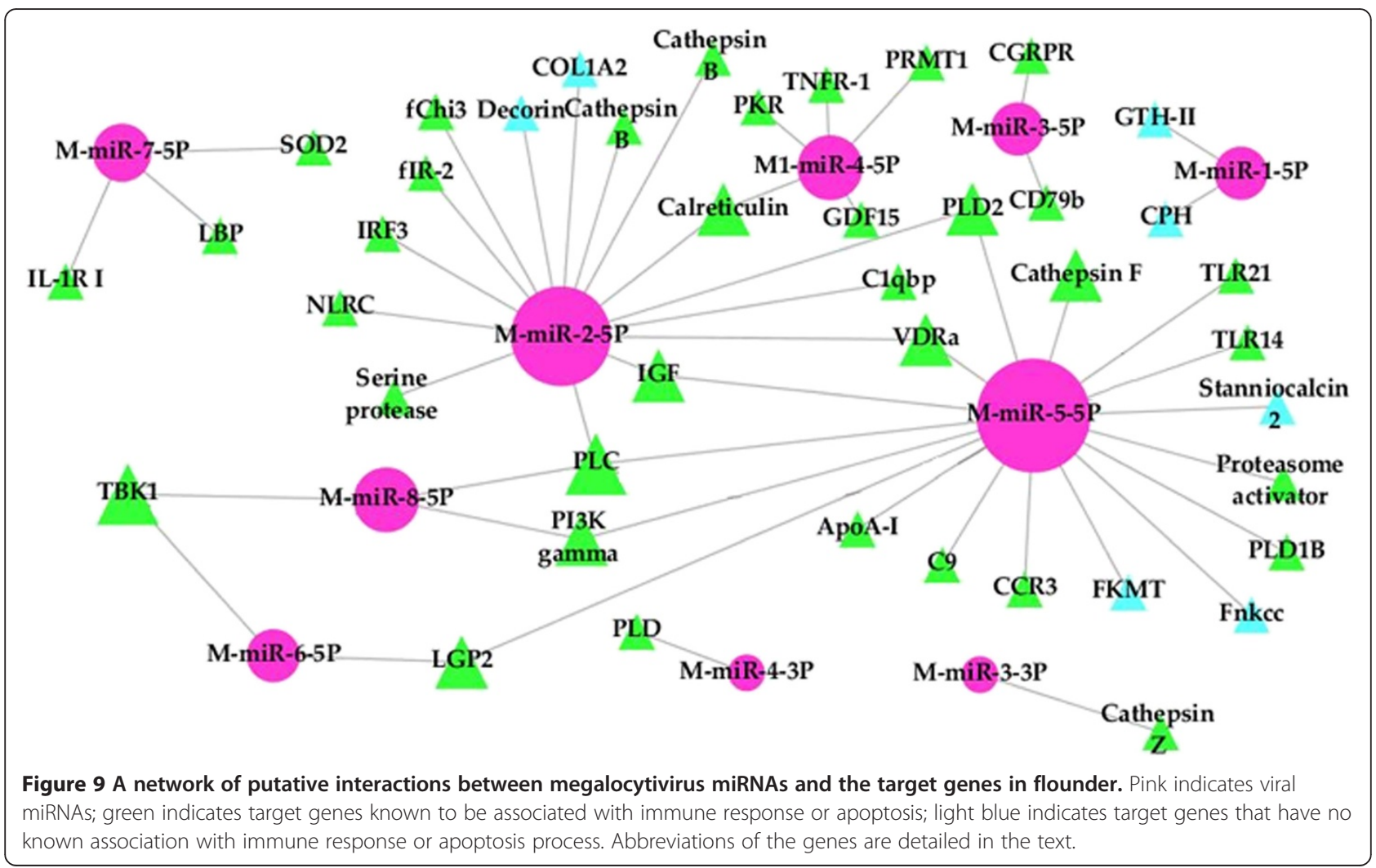


miRNAs are subverted by virus to serve as mediators of viral infection. Evidences of both situations have been demonstrated in higher vertebrates, e.g., the human miRNAs miR-146a and miR-29b are induced during EBV infection, which leads to downregulation of interferonresponsive genes [40-45].

For the 121 differentially expressed host miRNAs identified in our study, 243 putative target genes were predicted in flounder. GO and KEGG pathway analysis showed that the predicted target genes are involved in diverse biological processes ranging from fundamental cellular operations to stress response, suggesting that miRNAs may have a global impact on the host system. It is of note that the majority of the differentially expressed host miRNAs were downregulated at early infection time (2d pi). Since miRNAs function to suppress gene expression [46], this phenomenon implies that the genes associated with many crucial cellular pathways are probably upregulated in response to megalocytivirus infection. Of these downregulated miRNAs, pol-miR-19a-5p_L-1R + 1 is a homologue of the human miRNA hsa-miR-19a-5p, which regulates a wide range of pathways in many diseases through targeting PTEN (phosphatase and tensin homolog deleted on chromosome ten) [47], cyclin D1 [48], and TNF- $\alpha$ [49]. Of the putative target genes of the downregulated miRNAs, the transcription factor PU.1 is known to be required for Flt3 cytokine receptor expression and for the development of IL-9-producing T cells and dendritic cells [50,51], fIGF-IR-2 has been reported to protect cells from apoptosis [52,53], whereas cathepsin B is known to contribute to TNF- $\alpha$-mediated apoptosis $[54,55]$. Apoptosis is generally considered an innate response of the host to counteract viral infection [56]. Consequently, for virus in infection, it is necessary to inhibit the apoptotic process so to prevent premature destruction of the host cells and enable viral production at the later infection stage [57]. The observation in our study of both pro- and anti-apoptosis targets of miRNAs suggests that some of the flounder miRNAs operate to promote host defense, while others may serve for virus infection.

Another striking feature observed with the differentially expressed flounder miRNAs in our study is that at 10 $\mathrm{d}$ pi and $14 \mathrm{~d}$ pi, the numbers of upregulated miRNAs dramatically increased compared to those at $2 \mathrm{~d}$ pi to $6 \mathrm{~d}$ pi. Similar observations have been made with human epithelial A549 cells infected with H1N1 influenza virus [58]. The upregulated miRNAs in our study included pol-miR-146, whose homologues in mammals are known to function in a negative feedback pathway of TLR and cytokine signaling $[23,59]$ and to act as negative regulators of interferon signaling by targeting IRF5 and STAT-1 transcription factors [60]. Thus, in flounder, enhanced expression of pol-miR-146 may remove the negative holds on cytokine and interferon signaling, whereby augmenting antiviral defense. Two other upregulated miRNAs, polmiR-221-5p and pol-miR-221-3p, were predicted to target flounder phospholipase C. In humans, phospholipase $\mathrm{C}$ is a key enzyme that hydrolyzes phosphatidylinositol 4,5-bisphosphate to trigger calcium release from intracellular stores, which facilitates virus entry into host cells $[61,62]$. Given these previous findings, the upregulation of pol-miR-221-5p and pol-miR-221-3p may, through inhibiting phospholipase $C$ expression, represent a novel way to prevent viral spread in flounder.

Aside from host-encoded miRNAs, our study also discovered 9 novel viral miRNAs encoded by the RBIV-C1 genome. Most of the viral miRNAs are located within coding regions, which suggests the possibility that megalocytivirus may, like other viruses [63], use its coding capacity to the maximum. As observed with herpes simplex virus $[64,65]$, two megalocytivirus miRNAs were derived from the 5'- and 3'-arm of the same precursor miRNA. However, the reads of these two miRNAs are different, which is probably the result of difference in processing, as a recent report showed that the processing of $3 \mathrm{p}$ - and 5p-derived mature miRNAs depends on the RNase IIIB and RNase IIIA domains of Dicer respectively [66]. Two of the identified miRNAs, i.e. M-mir-7-5p and M-mir-4-5p, are not typical form of miRNA precursors, nevertheless they were considered miRNAs based on the observations that (i) the corresponding mature miRNAs were detected and identified with stem loop RT-PCR, and (ii) many of the predicted target genes of these miRNAs are grouped into innate immune response GO term and/or apoptotic process GO term, both which play crucial roles in antiviral defense or viral immune evasion. It is interesting that none of the megalocytivirus miRNAs shares homology with known viral miRNAs, which may be due to the fact that to date very little study on iridovirus miRNAs has been documented, and, except for a report on the miRNA of Singapore grouper iridovirus, an iridovirus of the genus Ranavirus [67], no miRNAs from other genera, including Megalocytivirus, have been identified. Another reason could be that in order to adapt rapidly to specific host environments, viral miRNAs are capable of higher rate of mutation and faster evolution compared to cellular miRNAs $[38,63]$. It is noteworthy that, unlike previous studies such as that by Skalsky et al., in which a miRNA of Kaposi's sarcoma-associated herpesvirus was found to share $100 \%$ seed sequence homology with a human miRNA [68], the viral miRNAs identified in our study failed to match any known host miRNAs. This observation suggests that megalocytivirus miRNAs may not be able to regulate the expression of host mRNAs through evolutionarily conserved target sites as reported for the viral miRNAs with orthologs in cellular miRNAs [38].

Target prediction and GO analysis showed that megalocytivirus miRNAs have putative targets in the 3'-UTRs of 
a number of immune genes. Of these genes, TLR14 is proposed to be a functional substitute of mammalian TLR6 and TLR10 and participate in immune response against a wide variety of pathogens in finfish [69], IRF3 is essential for inducible expression of Type I IFN genes [70,71], and $\operatorname{Ig} \beta$ is required for $B$ cell development and maintenance $[72,73]$. In addition to immune genes, genes involved in host apoptosis were also predicted as targets of megalocytivirus miRNAs. Of these genes, VDAC is a key functional target of the Bcl-2 family of proteins and involved in regulating mitochondrial membrane permeability during apoptosis [74], GDF-15 is a transcriptional target of p53 family members, and overexpression of GDF-15 promotes apoptosis in human breast and colorectal cell lines [75,76]. Other putative targets of megalocytivirus miRNAs include PKR, which is known to induce apoptosis by activation of the FADD/caspase 8 pathway and prevent virus replication by inhibiting translation of viral mRNAs through phosphorylation of eIF2 $\alpha[77,78]$. Taken together, these observations lend support to the notion that miRNAs facilitate megalocytivirus infection by manipulating host immune response and prolonging survival of infected host cells.

\section{Conclusions}

In conclusion, we in this study identified 9 novel megalocytivirus miRNAs and 381 flounder miRNAs, the latter including 130 novel miRNAs and 121 differently expressed miRNAs. The 9 viral miRNAs and the 121 differently expressed host miRNAs exhibited dynamic changes in expression during the course of viral infection. The putative targets of host and viral miRNAs were grouped into a wide range of functional categories, in particular those associated with immune defense/evasion and signal transduction. These results suggest that in teleost, as in higher vertebrates, miRNAs likely have profound effects on both host immune defense and viral infection. In addition, the large amount of novel miRNAs as well as their putative target genes identified in this study will serve as a useful source for future researches to investigate, from a new angle, the mechanisms of both viral infection and host defense in teleost.

\section{Availability of supporting data}

The data supporting the results of this article are included in the article and its additional files.

\section{Additional files}

Additional file 1: Primers for stem-loop RT-PCR

Additional file 2: The sequences and homologues of 381 flounder miRNAs.

Additional file 3: Expression frequency of flounder miRNAs.

Additional file 4: Putative miRNA targets in flounder.

Additional file 5: Putative target genes of differentially expressed host miRNAs associated with immune response.

\section{Abbreviations}

apoA-l: Apolipoprotein A-l; C1qbp: Complement component 1q subcomponent gamma polypeptide; C9: Complement component C9; CCR3: C-C chemokine receptor-3; CD79b: immunoglobulin $\beta$ (CD79B); cgrpr: Calcitonin gene-related peptide receptor; COL1A2: Type 1 collagen alpha2; $\mathrm{CPH}$ : Carboxypeptidase H; fChi3: chitinase3; fIR-2: IR-2 insulin receptor; FKMT: Fast skeletal muscle troponin; Fnkcc: Na-K-Cl cotransporter; GDF15: Growth differentiation factor 15; GTH-II: Gonadotropin beta subunit; IGF: Insulin-like growth factor I; IL-1R I: Interleukin-1 receptor type II; IRF3: Interferon regulatory factor 3 variant 1; LBP: Lipopolysaccharide-binding protein/bactericidal permeability-increasing protein; LGP2: ATP-dependent helicase LGP2; NLRC: NOD-like receptor C; PI3K gamma: Phosphoinositide 3kinase gamma; PKR: dsRNA-dependent protein kinase; PLC: Phospholipase C; PLD: Phospholipase D; PLD1B: Phospholipase D1B; PLD2: Phospholipase D2; PRMT1: Arginine methyltransferase 1; SOD2: Mn-superoxide dismutase; TBK1: TANK binding kinase 1; TLR14: Toll like receptor 14; TLR21: Toll-like receptor 21; TNFR-1: Tumor necrosis factor receptor-1; VDRa: Vitamin D receptor a.

\section{Competing interests}

The authors declare that they have no competing interests.

\section{Authors' contributions}

BCZ and LS conceived and designed the experiments, BCZ and JZ analyzed the data, and BCZ and LS wrote the paper. All authors read and approved the final manuscript.

\section{Acknowledgements}

This work was supported by the grants of the National Basic Research Program of China (2012CB114406) and the Taishan Scholar Program of Shandong Province.

\section{Author details}

${ }^{1}$ Key Laboratory of Experimental Marine Biology, Institute of Oceanology, Chinese Academy of Sciences, Qingdao 266071, China. ${ }^{2}$ Graduate University of the Chinese Academy of Sciences, Beijing 100049, China. ${ }^{3}$ Collaborative Innovation Center of Deep Sea Biology, College of Life Sciences, Zhejiang University, Hangzhou 310058, China.

Received: 10 March 2014 Accepted: 24 September 2014 Published: 8 October 2014

\section{References}

1. Pritchard CC, Cheng HH, Tewari M: MicroRNA profiling: approaches and considerations. Nat Rev Genet 2012, 13(5):358-369.

2. Boss IW, Renne R: Viral miRNAs and immune evasion. BBA-Gene Regul Mech 2011, 1809(11-12):708-714.

3. Chen YT, Kitabayashi N, Zhou XK, Fahey TJ, Scognamiglio T: MicroRNA analysis as a potential diagnostic tool for papillary thyroid carcinoma. Mod Pathol 2008, 21(9):1139-1146.

4. Lu J, Getz G, Miska EA, Alvarez-Saavedra E, Lamb J, Peck D, Sweet-Cordero A, Ebet BL, Mak RH, Ferrando AA, Downing JR, Jacks T, Horvitz HR, Golub TR: MicroRNA expression profiles classify human cancers. Nature 2005, 435(7043):834-838

5. Rosenfeld N, Aharonov R, Meiri E, Rosenwald S, Spector Y, Zepeniuk M, Benjamin H, Shabes N, Tabak S, Levy A, Lebanony D, Goren Y, Silberschein E, Targan N, Ben-Ari A, Gilad S, Sion-Vardy N, Tobar A, Feinmesser M, Kharenko O, Nativ O, Nass D, Perelman M, Yosepovich A, Shalmon B, Polak-Charcon S, Fridman E, Avniel A, Bentwich I, Bentwich Z, et al: MicroRNAs accurately identify cancer tissue origin. Nat Biotechnol 2008, 26(4):462-469.

6. Boeri M, Verri C, Conte D, Roz L, Modena P, Facchinetti F, Calabro E, Croce CM, Pastorino U, Sozzi G: MicroRNA signatures in tissues and plasma predict development and prognosis of computed tomography detected lung cancer. Proc Natl Acad Sci U S A 2011, 108(9):3713-3718.

7. Tili E, Michaille JJ, Costinean S, Croce CM: MicroRNAs, the immune system and rheumatic disease. Nat Clin Pract Rheum 2008, 4(10):534-541.

8. Hussain M, Torres S, Schnettler E, Funk A, Grundhoff A, Pijlman GP, Khromykh AA, Asgari S: West Nile virus encodes a microRNA-like small RNA in the 3 ' untranslated region which up-regulates GATA4 mRNA and facilitates virus replication in mosquito cells. Nucleic Acids Res 2012, 40(5):2210-2223. 
9. Singh CP, Singh J, Nagaraju J: A baculovirus-encoded microRNA (miRNA) suppresses its host miRNA biogenesis by regulating the exportin-5 cofactor ran. J Virol 2012, 86(15):7867-7879.

10. Guo XK, Zhang Q, Gao L, Li N, Chen XX, Feng WH: Increasing expression of microRNA 181 inhibits porcine reproductive and respiratory syndrome virus replication and has implications for controlling virus infection. J Virol 2013, 87(2):1159-1171.

11. Jopling CL, Yi MK, Lancaster AM, Lemon SM, Sarnow P: Modulation of hepatitis C virus RNA abundance by a liver-specific microRNA. Science 2005, 309(5740):1577-1581.

12. Song LP, Liu H, Gao SJ, Jiang W, Huang WL: Cellular microRNAs inhibit replication of the H1N1 influenza a virus in infected cells. J Virol 2010, 84(17):8849-8860.

13. Pfeffer S, Zavolan M, Grasser FA, Chien MC, Russo JJ, Ju JY, John B, Enright AJ, Marks D, Sander C, Tuschl T: Identification of virus-encoded microRNAs. Science 2004, 304(5671):734-736.

14. Skalsky RL, Cullen BR: Viruses, microRNAs, and host interactions. Annu Rev Microbiol 2010, 64:123-141

15. Stern-Ginossar N, Elefant N, Zimmermann A, Wolf DG, Saleh N, Biton M, Horwitz E, Prokocimer Z, Prichard M, Hahn G, Goldman-Wohl D, Greenfield C, Yagel S, Hengel H, Altuvia Y, Margalit H, Mandelboim O: Host immune system gene targeting by a viral miRNA. Science 2007, 317(5836):376-381.

16. Sullivan CS: New roles for large and small viral RNAs in evading host defences. Nat Rev Gene 2008, 9(7):503-507.

17. Gupta A, Gartner JJ, Sethupathy P, Hatzigeorgiou AG, Fraser NW: Anti-apoptotic function of a microRNA encoded by the HSV-1 latency-associated transcript. Nature 2006, 442(7098):82-85.

18. Sullivan CS, Grundhoff AT, Tevethia S, Pipas JM, Ganem D: SV40-encoded microRNAs regulate viral gene expression and reduce susceptibility to cytotoxic T cells. Nature 2005, 435(7042):682-686.

19. Stark TJ, Arnold JD, Spector DH, Yeo GW: High-resolution profiling and analysis of viral and host small RNAs during human cytomegalovirus infection. J Virol 2012, 86(1):226-235.

20. Wu ZH, Hao RZ, Li P, Zhang XA, Liu N, Qiu SF, Wang LG, Wang Y, Xue WZ, Liu K, Yang G, Cui JJ, Zhang CF, Song HB: MicroRNA expression profile of mouse lung infected with 2009 pandemic $\mathrm{H} 1 \mathrm{~N} 1$ influenza virus. Plos One 2013, 8(9):e74190.

21. Wang Y, Brahmakshatriya V, Zhu HF, Lupiani B, Reddy SM, Yoon BJ, Gunaratne PH, Kim JH, Chen R, Wang JJ, Zhou H: Identification of differentially expressed miRNAs in chicken lung and trachea with avian influenza virus infection by a deep sequencing approach. BMC Genomics 2009, 10(1):512.

22. Huang $T Z, X u D D$, Zhang XB: Characterization of host microRNAs that respond to DNA virus infection in a crustacean. BMC Genomics 2012, 13(1):159.

23. Ordas A, Kanwal Z, Lindenberg V, Rougeot J, Mink M, Spaink HP, Meijer AH: MicroRNA-146 function in the innate immune transcriptome response of zebrafish embryos to Salmonella typhimurium infection. BMC Genomics 2013, 14(1):696.

24. Sha Z, Gong G, Wang S, Lu Y, Wang L, Wang Q, Chen S: Identification and characterization of Cynoglossus semilaevis microRNA response to Vibrio anguillarum infection through high-throughput sequencing. Dev Comp Immunol 2014, 44(1):59-69.

25. Wu TH, Pan CY, Lin MC, Hsieh JC, Hui CF, Chen JY: In vivo screening of zebrafish microRNA responses to bacterial infection and their possible roles in regulating immune response genes after lipopolysaccharide stimulation. Fish Physiol Biochem 2012, 38(5):1299-1310.

26. Ariel E, Jensen BB: Challenge studies of European stocks of redfin perch, Perca fluviatilis L., and rainbow trout, Oncorhynchus mykiss (Walbaum), with epizootic haematopoietic necrosis virus. J Fish Dis 2009, 32(12):1017-1025.

27. Drennan JD, Ireland S, LaPatra SE, Grabowski L, Carrothers TK, Cain KD: High-density rearing of white sturgeon Acipenser transmontanus (Richardson) induces white sturgeon iridovirus disease among asymptomatic carriers. Aquac Res 2005, 36(8):824-827.

28. Plumb JA, Noyes AD, Graziano S, Wang J, Mao JH, Chinchar VG: Isolation and identification of viruses from adult largemouth bass during a 1997-1998 survey in the southeastern United States. J Aquat Anim Health 1999, 11(4):391-399.

29. Shi CY, Jia KT, Yang B, Huang J: Complete genome sequence of a Megalocytivirus (family Iridoviridae) associated with turbot mortality in China. Virol J 2010, 7(1):159.
30. Tapiovaara $\mathrm{H}$, Olesen $\mathrm{NJ}$, Linden J, Rimaila-Parnanen E, von Bonsdorff CH: Isolation of an iridovirus from pike-perch Stizostedion lucioperca. Dis Aquat Organ 1998, 32(3):185-193.

31. Zhang $M$, Sun $K$, Sun L: Regulation of autoinducer 2 production and luxS expression in a pathogenic Edwardsiella tarda strain. Microbiology 2008, 154(7):2060-2069.

32. Zhang M, Xiao ZZ, Hu YH, Sun L: Characterization of a megalocytivirus from cultured rock bream, Oplegnathus fasciatus (Temminck \& Schlege), in China. Aquac Res 2012, 43(4):556-564.

33. Wang HR, Hu YH, Zhang WW, Sun L: Construction of an attenuated Pseudomonas fluorescens strain and evaluation of its potential as a cross-protective vaccine. Vaccine 2009, 27(30):4047-4055.

34. Ambady $S, W u Z$, Dominko T: Identification of novel microRNAs in Xenopus laevis metaphase II arrested eggs. Genesis 2012, 50(3):286-299.

35. Fu YS, Shi ZY, Wu ML, Zhang JL, Jia L, Chen XW: Identification and differential expression of microRNAs during metamorphosis of the Japanese flounder (Paralichthys olivaceus). Plos One 2011, 6(7):e22957.

36. Ding SW, Voinnet O: Antiviral immunity directed by small RNAs. Cell 2007, 130(3):413-426.

37. Pedersen IM, Cheng G, Wieland S, Volinia S, Croce CM, Chisari FV, David M: Interferon modulation of cellular microRNAs as an antiviral mechanism. Nature 2007, 449(7164):919-U913.

38. Ghosh Z, Mallick B, Chakrabarti J: Cellular versus viral microRNAs in host-virus interaction. Nucleic Acids Res 2009, 37(4):1035-1048.

39. Sisk JM, Witwer KW, Tarwater PM, Clements JE: SIV replication is directly downregulated by four antiviral miRNAs. Retrovirology 2013, 10(1):95.

40. Cameron JE, Yin QY, Fewell C, Lacey M, McBride J, Wang X, Lin Z, Schaefer BC, Flemington EK: Epstein-Barr virus latent membrane protein 1 induces cellular MicroRNA miR-146a, a modulator of lymphocyte signaling pathways. J Virol 2008, 82(4):1946-1958.

41. Jopling CL, Schuetz S, Sarnow P: Position-dependent function for a tandem microRNA miR-122-binding site located in the hepatitis $C$ virus RNA genome. Cell Host Microbe 2008, 4(1):77-85.

42. Yeung ML, Bennasser $Y$, Myers TG, Jiang GJ, Benkirane M, Jeang KT: Changes in microRNA expression profiles in HIV-1-transfected human cells. Retrovirology 2005, 2(1):81

43. Houzet L, Yeung ML, de Lame V, Desai D, Smith SM, Jeang KT: MicroRNA profile changes in human immunodeficiency virus type 1 (HIV-1) seropositive individuals. Retrovirology 2008, 5(1):181.

44. Trobaugh DW, Gardner CL, Sun C, Haddow AD, Wang E, Chapnik E, Mildner A, Weaver SC, Ryman KD, Klimstra WB: RNA viruses can hijack vertebrate microRNAs to suppress innate immunity. Nature 2014, 506(7487):245-248.

45. Anastasiadou E, Boccellato F, Vincenti S, Rosato P, Bozzoni I, Frati L, Faggioni A, Presutti C, Trivedi P: Epstein-Barr virus encoded LMP1 downregulates TCL1 oncogene through miR-29b. Oncogene 2010, 29(9):1316-1328.

46. Nilsen TW: Mechanisms of microRNA-mediated gene regulation in animal cells. Trends Genet 2007, 23(5):243-249.

47. Pezzolesi MG, Platzer P, Waite KA, Eng C: Differential expression of PTEN-targeting microRNAs miR-19a and miR-21 in Cowden Syndrome. Am J Hum Genet 2008, 82(5):1141-1149.

48. Doebele C, Bonauer A, Fischer A, Scholz A, Reiss Y, Urbich C, Hofmann WK, Zeiher AM, Dimmeler S: Members of the microRNA-17-92 cluster exhibit a cell-intrinsic antiangiogenic function in endothelial cells. Blood 2010, 115(23):4944-4950.

49. Chen B, She SF, Li DT, Liu ZH, Yang XJ, Zeng ZR, Liu FB: Role of miR-19a targeting TNF-alpha in mediating ulcerative colitis. Scand I Gastroenterol 2013, 48(7):815-824.

50. Carotta S, Dakic A, D'Amico A, Pang SHM, Greig KT, Nutt SL, Wu L: The transcription factor pu. 1 controls dendritic cell development and Flt3 cytokine receptor expression in a dose-dependent manner. Immunity 2010, 32(5):628-641

51. Chang HC, Sehra S, Goswami R, Yao WG, Yu Q, Stritesky GL, Jabeen R, McKinley C, Ahyi AN, Han L, Nguyen ET, Robertson MJ, Perumal NB, Tepper RS, Nutt SL, Kaplan MH: The transcription factor PU.1 is required for the development of IL-9-producing T cells and allergic inflammation. Nat Immunol 2010, 11(6):527-U598.

52. Resnicoff M, Abraham D, Yutanawiboonchai W, Rotman HL, Kajstura J, Rubin R, Zoltick P, Baserga R: The insulin-like growth-factor-I receptor protects tumor-cells from apoptosis in-vivo. Cancer Res 1995, 55(11):2463-2469. 
53. Rubin R, Baserga R: Insulin-like growth-factor-I receptor - its role in cell-proliferation, apoptosis, and tumorigenicity. Lab Invest 1995, 73(3):311-331.

54. Guicciardi ME, Deussing J, Miyoshi H, Bronk SF, Svingen PA, Peters C, Kaufmann SH, Gores GJ: Cathepsin B contributes to TNF-alpha-mediated hepatocyte apoptosis by promoting mitochondrial release of cytochrome c. J Clin Invest 2000, 106(9):1127-1137.

55. Foghsgaard L, Wissing D, Mauch D, Lademann U, Bastholm L, Boes M, Elling F, Leist M, Jaattela M: Cathepsin B acts as a dominant execution protease in tumor cell apoptosis induced by tumor necrosis factor. J Cell Biol 2001, 153(5):999-1009.

56. Everett $H$, McFadden $G$ : Apoptosis: an innate immune response to virus infection. Trends Microbiol 1999, 7(4):160-165.

57. Cuconati A, White E: Viral homologs of BCL-2: role of apoptosis in the regulation of virus infection. Genes Dev 2002, 16(19):2465-2478.

58. Loveday EK, Svinti V, Diederich S, Pasick J, Jean F: Temporal- and strain-specific host microRNA molecular signatures associated with swine-origin $\mathrm{H} 1 \mathrm{~N} 1$ and avian-origin H7N7 influenza A virus infection. J Virol 2012, 86(11):6109-6122.

59. Boldin MP, Taganov KD, Rao DS, Yang LL, Zhao JL, Kalwani M, Garcia-Flores Y, Luong M, Devrekanli A, Xu J, Sun G, Tay J, Linsley PS, Baltimore D: miR-146a is a significant brake on autoimmunity, myeloproliferation, and cancer in mice. J Exp Med 2011, 208(6):1189-1201.

60. Tang YJ, Luo XB, Cui HJ, Ni XM, Yuan M, Guo YZ, Huang XF, Zhou HB, de Vries N, Tak PP, Chen S, Shen N: MicroRNA-146a contributes to abnormal activation of the type I interferon pathway in human lupus by targeting the key signaling proteins. Arthritis Rheum 2009, 60(4):1065-1075.

61. Fukami K, Inanobe S, Kanemaru K, Nakamura Y: Phospholipase C is a key enzyme regulating intracellular calcium and modulating the phosphoinositide balance. Prog Lipid Res 2010, 49(4):429-437.

62. Bozym RA, Morosky SA, Kim KS, Cherry S, Coyne CB: Release of intracellular calcium stores facilitates coxsackievirus entry into polarized endothelial cells. PLoS Pathog 2010, 6(10):e1001135.

63. Sullivan CS, Grundhoff A: Identification of viral microRNAs. Methods Enzymo 2007, 427:3-23.

64. Jurak I, Silverstein LB, Sharma M, Coen DM: Herpes simplex virus is equipped with RNA- and protein-based mechanisms to repress expression of ATRX, an effector of intrinsic immunity. J Virol 2012, 86(18):10093-10102

65. Umbach JL, Wang K, Tang S, Krause PR, Mont EK, Cohen Jl, Cullen BR: Identification of viral microRNAs expressed in human sacral ganglia latently infected with herpes simplex Virus 2. J Virol 2010, 84(2):1189-1192.

66. Gurtan AM, Lu V, Bhutkar A, Sharp PA: In vivo structure-function analysis of human Dicer reveals directional processing of precursor miRNAs. RNA 2012, 18(6):1116-1122

67. Yan Y, Cui HC, Jiang SS, Huang YH, Huang XH, Wei SN, Xu WY, Qin QW: Identification of a novel marine fish virus, singapore grouper iridovirus-encoded microRNAs expressed in grouper cells by solexa sequencing. Plos One 2011, 6(4):e19148.

68. Skalsky RL, Samols MA, Plaisance KB, Boss IW, Riva A, Lopez MC, Baker HV, Renne R: Kaposi's sarcoma-associated herpesvirus encodes an ortholog of miR-155. J Virol 2007, 81(23):12836-12845.

69. Aoki T, Hikima J, Hwang SD, Jung TS: Innate immunity of finfish: primordial conservation and function of viral RNA sensors in teleosts. Fish Shellfish Immunol 2013, 35(6):1689-1702.

70. Sato M, Suemori H, Hata N, Asagiri M, Ogasawara K, Nakao K, Nakaya T, Katsuki M, Noguchi S, Tanaka N, Taniguchi T: Distinct and essential roles of transcription factors IRF-3 and IRF-7 in response to viruses for IFN-alpha/beta gene induction. Immunity 2000, 13(4):539-548.

71. Honda K, Yanai H, Negishi H, Asagiri M, Sato M, Mizutani T, Shimada N, Ohba Y, Takaoka A, Yoshida N, Taniguchi T: IRF-7 is the master regulator of type-I interferon-dependent immune responses. Nature 2005 434(7034):772-777.

72. Reichlin A, Hu Y, Meffre E, Nagaoka H, Gong SC, Kraus M, Rajewsky K, Nussenzweig MC: $B$ cell development is arrested at the immature $B$ cell stage in mice carrying a mutation in the cytoplasmic domain of immunoglobulin beta. J Exp Med 2001, 193(1):13-23.

73. Meffre $E$, Nussenzweig MC: Deletion of immunoglobulin $\beta$ in developing B cells leads to cell death. Proc Natl Acad Sci U S A 2002, 99(17):11334-11339.
74. Tsujimoto Y, Shimizu S: The voltage-dependent anion channel: an essential player in apoptosis. Biochimie 2002, 84(2-3):187-193.

75. Osada M, Park HL, Park MJ, Liu JW, Wu GJ, Trink B, Sidransky D: A p53-type response element in the GDF15 promoter confers high specificity for p53 activation. Biochem Biophys Res Commun 2007, 354(4):913-918.

76. Li PX, Wong J, Ayed A, Ngo D, Brade AM, Arrowsmith C, Austin RC, Klamut HJ: Placental transforming growth factor-beta is a downstream mediator of the growth arrest and apoptotic response of tumor cells to DNA damage and p53 overexpression. J Biol Chem 2000, 275(26):20127-20135.

77. Balachandran S, Roberts PC, Brown LE, Truong H, Pattnaik AK, Archer DR, Barber GN: Essential role for the dsRNA-dependent protein kinase PKR in innate immunity to viral infection. Immunity 2000, 13(1):129-141.

78. Gil J, Esteban M: Induction of apoptosis by the dsRNA-dependent protein kinase (PKR): Mechanism of action. Apoptosis 2000, 5(2):107-114.

doi:10.1186/1471-2164-15-878

Cite this article as: Zhang et al:: In-depth profiling and analysis of host and viral microRNAs in Japanese flounder (Paralichthys olivaceus) infected with megalocytivirus reveal involvement of microRNAs in host-virus interaction in teleost fish. BMC Genomics 2014 15:878.

\section{Submit your next manuscript to BioMed Central and take full advantage of:}

- Convenient online submission

- Thorough peer review

- No space constraints or color figure charges

- Immediate publication on acceptance

- Inclusion in PubMed, CAS, Scopus and Google Scholar

- Research which is freely available for redistribution 